\section{Increased Sensitivity of One-Tube, Quantitative RT-PCR}

BioTechniques 29:702-706 (October 2000)

With the introduction of real-time, fluorescence-based $5^{\prime}$ nuclease PCR $(3,4)$ and instruments such as the ABI PRISM $^{\text {TM }} 7700$ (TaqMan ${ }^{\circledR}$ ) sequence detector (Applied Biosystems, Foster City, CA, USA), quantitative RT-PCR is now a widely accepted method for measuring gene expression levels. Quantitative RTPCR is a sensitive technique and is particularly useful for the analysis of sam ples containing limited amounts of nucleic acids, such as in clinical tissues (2). When quantitating these small amounts of RNA and/or very low-abundance mRNA species, obtaining maximum sensitivity from a quantitative RTPCR is extremely important. While consecutive rounds of nested PCR are often used to obtain maximum sensitivity, this is difficult to achieve and still maintain accurate quantitation. Furthermore, multiple rounds of PCR increase the risk of contamination, a serious problem when working at the desired sensitivity levels. One-tube RT-PCR (RT and PCR in the same tube using the reverse PCR primer for the RT) reduces the risk of contamination when using the ABI PRISM 7700 because the reaction tubes are never opened.

Theoretically, a one-tube procedure should have the same sensitivity as a two-step approach (separate RT followed by PCR), but in practice this is not the case (1). We have found that the sensitivity of one-tube RT-PCR is limited by the relative nonspecificity of the RT step. This nonspecificity arises from the fact that the RT is carried out at relatively low temperature and without a hot start, thus allowing nonspecific priming by both the desired RT "reverse" primer and also from the "forward" PCR primer. As the amount of target decreases in the input RNA sample, priming artifacts from the coldstart RT process can compete with, and reduce the efficiency of, PCR amplification of the desired target sequence. Thus, as RNA input decreases in a onetube procedure, nonspecific side reac- tions eventually out-compete the desired reaction, and no specific product is generated. In a two-step or nested RT-PCR procedure, specificity can be achieved with the use of hot-start PCR and a primer set $5^{\prime}$ upstream from the RT primer. However, this is not the case in a one-tube procedure unless one is willing to open the reaction tube to add new primers (thus making it a one-tube but two-step procedure). We hypothesized that by using an external RT primer and keeping the RT and PCR primers separated during the RT step, we should be able to maintain PCR specificity and therefore sensitivity in a one-tube RT-PCR. Here, we report a modified one-tube RT-PCR assay that greatly increases sensitivity and can be used for quantitative RT-PCR on the ABI PRIS M7700.

Standard one-tube reactions were set up for $\beta$-glucuronidase ( $\beta$-gus) mRNA in $50-\mu \mathrm{L}$ volumes with the following final concentrations: $20 \mathrm{nM}$ $\beta$-gus RT primer (5'-TTTGGTTGTCTCTGCCGAGT-3'), $100 \mathrm{nM}$ each $\beta$-gus PCR primer (GUS-F, 5'-CTCATTTGGAATTTTGCCGATT-3'; GUS-R, 5'-CCGAGTGAAGATCCCCTTTTTA-3'), 100 nM $\beta$-gus probe (5'-6-fam-TGAACAGTCACCGACGAGAGTGCTGG-tamra-3'), 1× TaqMan reaction buffer (Applied Biosystems), $5.5 \mathrm{mM} \mathrm{MgCl}_{2}, 300 \mu \mathrm{M}$ each dNTP, 20 U RNase inhibitor, 62.5 U SUPERSCRIPT II ${ }^{\mathrm{TM}}$ reverse transcriptase (Life Technologies, Rockville, MD, USA) and 1.25 U AmpliTaq Gold ${ }^{\circledR}$ (Applied Biosystems).

In the modified procedure, physical separation between the RT reaction mixture and the PCR primers was achieved by the use of AmpliWax ${ }^{\circledR}$ PCR gem 50 (Applied Biosystems). First, the $\beta$-gus PCR primers were pipetted into the PCR plate in a final $5.0-\mu \mathrm{L}$ volume. One PCR gem 50 was placed in each well, the wells were capped and the plate was centrifuged briefly to avoid the adherence of reagents to the tube wall above the wax barrier. The plate was then heated to $80^{\circ} \mathrm{C}$ for $2 \mathrm{~min}$ and cooled to $4^{\circ} \mathrm{C}$ to produce a wax barrier. A $45-\mu \mathrm{L}$ upper layer was then pipetted into each well. This mixture contained the $\beta$-gus RT primer, the RNA, RNase inhibitor and SUPERSCRIPT II reverse transcriptase.
Both layers were formulated to contain all of the remaining reaction components (buffer, nucleotides, $\mathrm{MgCl}_{2}$ ) at the concentrations described above. The presence of AmpliTaq Gold in the $\mathrm{RT}$ layer is inconsequential because this enzyme is inactive until heated to $95^{\circ} \mathrm{C}$.

All reactions were carried out on the ABI PRISM 7700 with the following thermocycler conditions: $48^{\circ} \mathrm{C}$ hold for 30 min, $95^{\circ} \mathrm{C}$ hold for $12 \mathrm{~min}$, followed by 40 cycles of $95^{\circ} \mathrm{C}$ for $20 \mathrm{~s}$ and $60^{\circ} \mathrm{C}$ for 1 $\mathrm{min}$. The wax layer remained intact for the RT step at $48^{\circ} \mathrm{C}$ but was melted during the $12-\mathrm{min}, 95^{\circ} \mathrm{C}$ AmpliTaq Gold activation step, thus allowing the two layers to mix before the PCR begins. Data were analyzed with Applied Biosystems' sequence detection software.

First, we evaluated the effect of the wax layer on the fluorescence detection in the TaqMan assay to determine the extent of fluorescence quenching by the wax. Using randomly primed cDNA from a lung adenocarcinoma cell line (A549), we performed 20 replicates of PCR for $\beta$-gus with and without the wax layer. The results showed no decrease in the overall fluorescence $(P=$ $0.935)$ and no change in the cycle threshold value $(P=0.55)$ between the two groups when compared by the independent samples t-test.

To compare the sensitivity of the one-tube RT-PCR with and without the wax, we used serial dilutions of spleen total RNA (Clontech Laboratories, Palo Alto, CA, USA) from $5 \mathrm{ng}$ to $10 \mathrm{pg}$. The results of the RT-PCR without the wax layer showed that the fluorescence $(\Delta \mathrm{Rn})$ was weak even at $5 \mathrm{ng}$ RNA input and decreased further by an average factor of $75 \%$ every dilution (Figure 1A). As a result, the 200-pg sample fell below the threshold for detection. How ever, with the use of the wax layer, we saw that the $\Delta \mathrm{Rn}$ remained essentially the same down to the 40-pg dilution, and only at $10 \mathrm{pg}$ was there a $60 \%$ drop in the $\Delta \mathrm{Rn}$ (Figure 1B). Thus, our modified procedure resulted in at least a 20fold increase in sensitivity. The efficiency (E) of the RT-PCR (as calculated by the formula $E=10^{(1 /-s)}-1$, where "s" is the slope of the standard curve from the dilutions) (5) was also improved by the use of the wax $(67 \%$ without wax and $77 \%$ with wax). A $10-\mu \mathrm{L}$ aliquot of each reaction was run out on a $10 \%$ 


\section{Benchmarks}

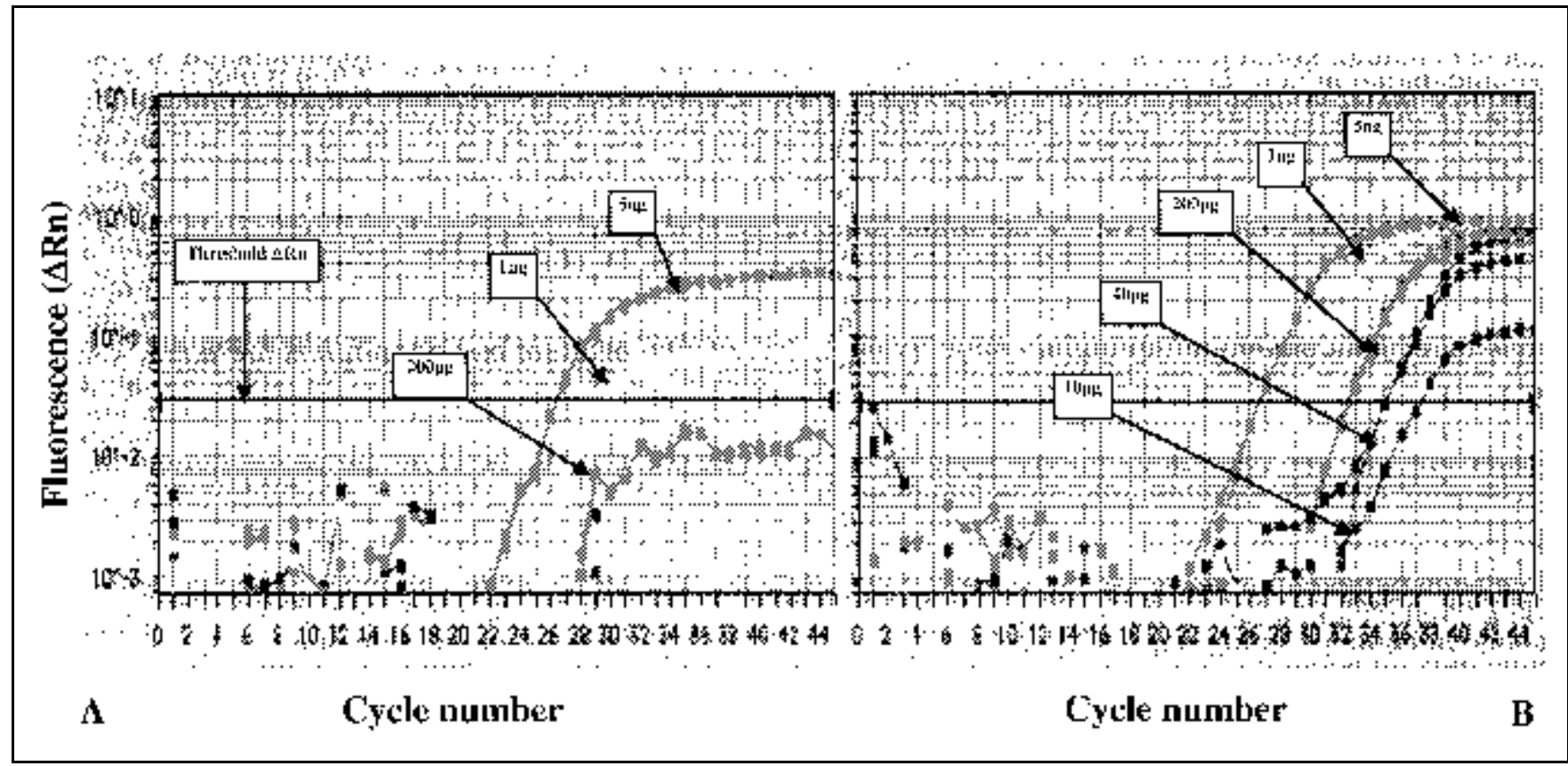

Figure 1. Sensitivity of one-step RT-PCR. Comparison of the sensitivity of one step RT-PCR with and without AmpliWax PCR gems to separate the RT and PCR layers. RT-PCR was carried out for $\beta$-gus mRNA with decreasing amounts of total RNA input to determine sensitivity of the two methods. (A) No wax; (B) with wax.

non-denaturing polyacrylamide gel and stained with ethidium bromide (Figure 2). With the wax layer, the 81-bp product, corresponding to the expected size, was visible in all but the 10-pg RNA dilution (demonstrating the extra sensitiv-

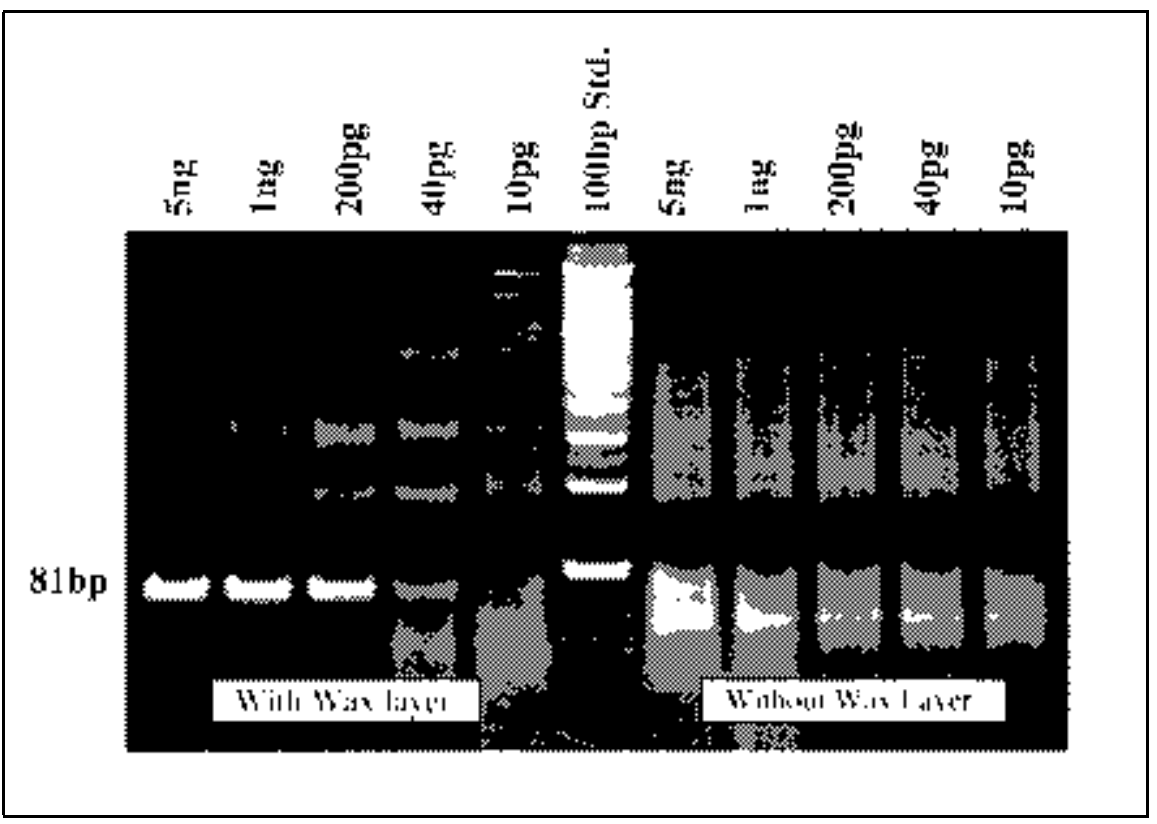

Figure 2. One-step RT-PCR amplification products. Polyacrylamide gel of the $\beta$-gus PCR products (81bp) generated in the experiment shown in Figure 1. Increased specificity is obtained with the wax layer procedure. ity of TaqMan detection versus ethidium bromide). In the reactions without wax, however, no reactions produced a clean signal at $81 \mathrm{bp}$. Instead, there was a smear of nonspecific products at all RNA concentrations.

The same experiments were performed using Sensiscript RT ${ }^{\circledR}$ (Qiagen, Valencia, CA, USA). With this enzyme, PCR product was just detectable down to the 40-pg dilution even without the use of the wax layer. However, the total fluorescence continued to drop with each consecutive dilution. With the addition of the wax, the $\Delta \mathrm{Rn}$ remained constant, and detection was easily achieved down to $10 \mathrm{pg}$. Notably, the efficiency of this one-tube reaction was near $100 \%$ (measured using the methods described above). Thus, the sensitivity of the one-tube RT-PCR for the $5^{\prime}$ fluorogenic assay in the ABI PRISM 7700 is significantly enhanced by the use of the AmpliWax PCR gem 50. PCR gems were originally designed to facilitate hot start PCR, but this is no longer necessary with new enzymes for automatic hot start. Here, we show that these same AmpliWax PCR gems are beneficial in the context of a one-step quantitative RT-PCR. Furthermore, by eliminating the need to open the PCR tubes, we minimize the occurrence of cDNA or PCR product contamination. Finally, the preservation of PCR specificity facilitates the amplification of the desired product, and as such, is relevant even in non-quantitative end-point assays. 


\section{REFERENCES}

1.Battaglia, M., P. Pedrazzoli, B. Palermo, A. Lanza, F. Bertolini, N. Gibelli, G.A. Da Prada, A. Zambelli et al. 1998. Epithelial tumour cell detection and the unsolved problems of nested RT-PCR: a new sensitive one step method without false positive results. Bone Marrow Transplant 22:693-698.

2.Collins, C., J.M. Rommens, D. Kowbel, T. Godfrey, M. Tanner, S.I. Hwang, D. Polikoff, G. Nonet et al. 1998. Positional cloning of ZNF217 and NABC1: genes amplified at 20q13.2 and overexpressed in breast carcinoma. Proc. Natl. Acad. Sci. USA 95:8703-8708.

3.Gibson, U.E., C.A. Heid and P.M. Williams. 1996. A novel method for real time quantitative RT-PCR. Genome Res. 6:995-1001.

4.Heid, C.A., J. Stevens, K.J. Livak and P.M. Williams. 1996. Real time quantitative PCR. Genome Res. 6:986-994.

5.PE Applied Biosystems User Bulletin \#2. 1997. Relative quantitation of gene expression. Applied Biosystems, Foster City, CA.

This work was supported in part by the George Heckman Memorial Institutional
Research grant no. 60-002-40-IRG from the American Cancer Society. Address correspondence to Dr. Tony E. Godfrey, C800, Presbyterian University Hospital, 200 Lothrop Street, Pittsburgh, PA 15213, USA. e-mail: godfreyte@msx.upmc.edu

Received 10 March 2000; accepted 19 June 2000.

S. Raja, J.D. Luketich, L.A. Kelly, D.W. Ruff ${ }^{1}$ and T.E. Godfrey

University of Pittsburgh Medical Center

Pittsburgh, PA

${ }^{1}$ Applied Biosystems

Foster City, CA, USA

\section{Estimation of Relative mRNA Content by Filter Hybridization to a Polyuridylic Probe}

BioTechniques 29:706-714 (October 2000)

Accurate measurement of changes in the expression of specific genes requires reliable normalization to total mRNA levels. While normalization to the level of expression of a specific "housekeeping" gene can give a reasonable estimate in some cases, expression of such housekeeping genes may not remain constant after exposure to stress and often varies between different cell types (2). In our experience, a more reliable approach has been the normalization of the relative polyadenylated (polyA) tract content of the compared samples. We have developed an 